\title{
O HOMEM NO LIVRO DAS CAUSAS
}

Jan Ter Reegen*

SINTESE - Um dos livros mais comentados na Idade Média foi o Liber de causis, também conhecido como $O$ livro da suprema felicidade. Trata-se de um pequeno texto, baseado na obra Elementos teológicos de Proclo. Embora sejam poucas as referências diretas ao homem ou à Ética, contudo, é possivel elaborar, em linhas gerais, a partir dele, tanto uma Antropologia como uma Ética.

PALAVRAS-CHAVES - Liber de causis. Proclo. Neoplatonismo. Homem. Ética.
ABSTRACT - One of the most commented books in the Middle Ages was the Liber de causis, also known as The book of supreme felicity, which is based on Proclus' Theological elements. Although there are few explicit references to man or ethics, it is possible to outline from this text both an anthropology and an ethics.

KEY WORDS - Liber de causis. Proclus. Neoplatonism. Man. Ethics.

\section{Introdução}

Uma das obras mais influentes, trazida do árabe, na grande invasão dos textos dos séculos XII e XIII, é sem dúvida o anônimo Liber de causis, também conhecida como $\mathrm{O}$ Livro da suprema bondade (em árabe: Kalam fi mahd alkhair).

O que é este famoso livro? Constitui-se de uma seqüência de 31 ou 32 Proposições, ou Capítulos, cada uma com comentários, apresentada "modo euclidiano" e que na sua forma segue a sua fonte principal, a Elementos teológicos, do famoso neoplatônico Proclo.

É uma obra relativamente pequena; a tradução em inglês de Dennis J. Brand, por exemplo, não contém mais de 26 páginas, com introdução e notas o volume conta com 58 páginas. Não obstante esse tamanho reduzido, o livro exerceu uma grande influência na Idade Média, sobretudo no século XIII.

Esta constatação pode ser deduzida, sobretudo, de dois fatos concretos:

* Universidade Estadual do Ceará - UECE. Instituto Teológico e Pastoral - ITEP.

\begin{tabular}{|l|l|l|l|l|l|}
\hline VERITAS & Porto Alegre & v. 44 & n. 3 & Setembro 1999 & p. 533-539 \\
\hline
\end{tabular}


1. O famoso Livro do Estudante, documento encontrado por Grabman, elaborado por um mestre da Faculdade das Artes de Paris entre os anos 1230-1240, diz que a Metafísica é estudada em três livros, entre os quais é citado o Livro das Causas: "et ibi agitur de substantiis divinis in quantum sunt principia essendi et influendi unam in alteram, secundum quos ibidem habetur quod omnis substantia superior influit in suam causam." Trata-se de uma espécie de "vade-mecum" destinada ao estudante que está se preparando para seus exames.

2. A sua admissão oficial nos programas universitários, como consta da famosa Carta de 19 de março de 1255, regulamentando o estatuto da Faculdade das Artes de Paris: o texto do Livio das Causas deve ser "lido" como outras obras de Aristóteles também devem ser lidas, durante sete semanas (veja a atribuição, ainda, a Aristóteles). ${ }^{2}$

Este uso generalizado, explica, igualmente, o fato de vários filósofos importantes da época terem elaborado comentánios a respeito do Livro das Causas, como, por exemplo, Roger Bacon, em Oxford, e Tomás de Aquino e Siger de Brabantia, entre outros.

Toda essa divulgação e presença do Livro das Causas no século XIII fizeram Magnard, comentando na sua introdução à edição francesa o fato que existem poucas traduções existentes, escrever:... aquela obra pequena, sempre citada, mas raramente disponivel para o leitor atual. ${ }^{3}$

Essa importância é, ainda, reforçada pela opinião corrente da época que atribuiu a obra a Aristóteles, seja na totalidade, seja em parte, como Alberto Magno e quase todos os comentaristas citados: a autoridade do "Filósofo" recai sobre o livro e dá uma dimensão especial ao seu conteúdo. ${ }^{4}$

Essa suposta autoria de Aristóteles é derrubada pelo comentário - Expositio de São Tomás de Aquino, em 1272, ao descobrir a sua dependência da obra de Proclo Elementos teológicos, sem porém negar a tendência de considerar o Livro das Causas uma espécie de complemento da metafísica aristotélica.

Mas, quem é realmente 0 autor do LdC? Não se pode, ao menos no atual estado das investigações, chegar a nenhum nome concreto. As várias tentativas levaram a uma única conclusão: o Livro das Causas é um escrito que tem suas raizes no neoplatonismo tardio, mas traduzido e adaptado pelos árabes, no ambiente religioso-cultural de Bagdá entre 900-1000, e trazido por eles para Espanha, onde na cidade de Toledo foi traduzido por Gerardo de Cremona. Essa conclusão justifica plenamente a opinião de São Tomás, que disse "[...] in arábico vero invenitur hic liber qui apud latinos De Causis dicitur, quem constat de arábico esse translatum et in graeco penitus non haberi".

\footnotetext{
H. D. Saffrey, em Sancti Thomae de Aquino super Librum de causis expositio, Fribourg, 1954, p. XIX.

van Steenbergen, Philosophie au XIIItene siècle, Louvain, 1991.

3 em; La Demeure del'être, autour d'un anonyme. Étude et traduction du Liber de causis. Paris: Vrin, 1990, p. 23 segs.

4 Veja a respeito: Alain de Libera, Albert le Grand, Vrin, 1990.

5 Saffrey, o.c., 3, 5-7.
} 
O contexto neoplatônico de suas fontes, tanto a principal - Elementos Teológicos de Proclo - como as outras - entre as quais as Enéadas de Plotino - determina o seu conteúdo, que é uma descrição da Causa Primeira, sua essência, sua ação, suas relações com as causas segundas. Para o autor desconhecido do Livro das Causas, o universo é um cosmos, no sentido clássico da palavra: uma ordem estruturada em conformidade com leis, que são - neste caso - as da filosofia neoplatônica. O princípio da causalidade é o mais fundamental das leis do neoplatonismo. O universo é considerado como um conjunto de causas e efeitos - de causas primárias e secundárias, de causas mais altas e mais baixas. As causas primárias são mais importantes do que as secundárias, conseqüentemente também o serão os seus efeitos. A Causa Primeira, a inteligência e a alma são as três causas primárias. Dessas três a Causa Primeira é, sem dúvida alguma, o Deus bendito sublime da fé monoteista. Deus é antes da eternidade, está acima do ser, é absolutamente transcendente e supera qualquer conhecimento ou descrição. A Causa Prïmeira, entretanto, estende sua influência, que se diz e de forma explicita, criadora sobre todas as coisas: dá o ser, cobra com perfeições, e governa com uma providência absoluta. Numa única "emanação", a Causa Primeira, que é a própria Bondade e Riqueza, faz jorrar, de forma uniforme, todas as perfeições. A diversidade das perfeições e dons não têm sua origem na Causa Primeira, o Deus Uno e Vero, mas sim nos que as recebem, porque estes receptores são múltiplos.

A inteligência é a primeira criatura, ela coexiste com a eternidade. Juntamente com a alma, a inteligência pode ser chamada de "constituindo-se a si mesma", isto é, ao contemplar a Causa Primeira a inteligência e a alma se repletam com perfeições. As inteligências são as substâncias separadas, também chamadas de anjos; são substâncias incorporais, simples - não compostas - que se entendem a si mesmas intuitivamente, sem necessidade de raciocínio, sem movimento ou extensão, então, sem intermédio de nada.. A inteligência é subdividida e hierarquicamente organizada, a primeira inteligência divina ocupando a posição mais alta e as inteligências simples o nível mais baixo. É através da inteligência que a força criadora da Causa Primeira se estende sobre todas as coisas.

A alma está entre a natureza e a inteligência. Ela é apresentada como o horizonte do ser, porque é ligada à eternidade "de forma fraca", mas, mesmo assim, ainda está acima do tempo. Por causa disso deve ser considerada como a ponte entre tempo e eternidade, entre inteligência e natureza. A Causa Primeira colocou a alma como o substrato sobre que a inteligência realiza a sua atividade. Como a inteligência, a alma também é subdividida e hierarquicamente organizada, sendo o lugar mais importante da alma primeira intelectual e mais baixo das almas simples. Abaixo da alma está a natureza, o universo sensivel. A posição mais alta na natureza é para os corpos celestiais e o tempo, a mais baixa é destinada à matéria sensivel. $^{7}$

6 Veja a respeito os estudos penetrantes de Cristina D'Ancona Costa: Recherches sur le Livre des causes, Vrin, 1995.

7 Veja D. Brand, The book of causes (Liber de causis), Marquette University Press, 1981, p. 11-12. 
Do homem, de forma inequívoca e explicita, usando o vocábulo só se fala uma única vez: na Proposição Ia, 6-11. ${ }^{8}$ O homem é aqui apresentado não para explicar qual a sua essência ou seu modo de ser, mas sim para apresentar a causalidade da Causa Primeira que envolve tudo. Vejamos o texto:

"Toda causa primeira influencia mais o seu efeito do que a causa universal segunda [...]. Ilustramos isto, então, pelo exemplo do ser, do vivo e do homem. Assim ocorre, porque convém que a coisa seja em primeiro lugar um ser (ou: ente), em seguida vivo, e, finalmente, homem. $O$ vivo, então, é a causa próxima do homem, o ser a causa longínqua. O ser é, então, mais expressivamente causa do homem do que o vivo, porque ele é causa do vivo, que é causa do homem. Da mesma forma, quando se afirma a racionalidade como causa do homem, o ser é causa do homem mais expressivamente do que a racionalidade, porque ele é causa da causa dessa. E a prova daquilo que se disse é que, quando se retira do homem o poder racional, não há mais um homem, mas um ser vivo, respirando e sensível. E quando se the tirar o vivo, não sobra mais o vivo, mas resta o ser, porque não lhe é retirado o ser, mas o vivo, porque a causa não é eliminada em razão da retirada do seu efeito; o homem continua, então, um ser. Quando, pois, um indivíduo não é um homem, é um animal, quando não é um animal, é tão somente um ser vivo."

Coloca-se, aqui, uma causalidade gradativa: a primeira coisa que o homem recebe é o ser. Isto quer dizer que como homem, como ser determinado pela racionalidade, é criado pela Causa Primeira. Depois, este ser é caracterizado como vivo. Finalmente este ser vivo é homem ao receber as "bonitates", as perfeições que lhe advêm através da inteligência e da alma.

O que, então, num processo de cornupção se perde em primeiro lugar é a racionalidade, enquanto vida e respiração permanecem; desaparecendo também estes, sinais que são da vida, fica um corpo inanimado, isto sem "anima", sem alma, e fica, então, somente o um ser.

Este ser é o resultado da Causa Primeira, que fica, mesmo sem a presença dos efeitos das causas primárias segundas, a saber a inteligência e a alma. Não há, portanto, nenhuma condição de atuação por parte da inteligência e da alma sem a presença do efeito da Causa Primeira, o ser: não pode haver determinações, sem a existência de o que determinar.

O homem, conseqüentemente, é criatura de Deus, em que está presente a força da inteligência e da alma.

Depois desta explícita menção do homem, não se encontra mais o vocábulo homem no Livro das Causas. Deve-se, então, dizer que com isso se esgota todo o potencial do Livro das Causas de nos aprofundar a imagem do homem?

Algumas Proposições, assim me parece, podem nos esclarecer a essência do homem na concepção deste documento. Começaremos com a Proposição 5 (6), de que citaremos o "caput": "A causa primeira é superior à descrição, e as línguas fracassam ao falar dela, quando descrevem o seu ser, porque ela está acima de

8 A tradução portuguesa do Livro das causas é a do Jan G. J. ter Reegen, O Livro das causas - Liber de causis, uma introdução e tradução. Tese para Livre-Docência em Filosofia Antiga, UECE, 1999. 
toda causa, e dela podemos falar somente através das causas segundas, que são luminadas pela luz da causa primeira". A primeira, e mais óbvia, conclusão desta afirmação é que existe entre o homem e o seu Primeiro Princípio uma distância fundamental: homem nenhum tem acesso ao Ser Supremo, senão através das causas segundas. Não precisa ser dito nem explicado que aqui estamos, da forma mais clara possivel, diante da filosofia negativa ${ }^{9}$ e suas implicações. A imagem da Luz que ilumina tudo, mas numa iluminação gradativa e que se torna conhecida através das coisas iluminadas, mas nunca é conhecida em si mesma, de forma total, completa esta constatação.

Em seguida, encontra-se nesta proposição, os seus comentánios explicitam esta constatação - como veremos - uma descrição do processo do conhecimento dos seres racionais, tanto inteligíveis como sensiveis, no caso o homem.

Pode-se dizer que quanto mais se conhece, no sentido de quantidade de coisas, tanto menos se sabe: é entrando no mistério e descobrindo a sua profundidade que se chega a um conhecimento mais envolvente. Descobre-se a fonte de onde tudo procede, em vez de muitas imagens, vê-se a forma original. O homem chega a conhecer as coisas de uma maneira indireta, através de imagens; isto é bem diferente do modo de conhecer das causas primárias que conhecem "olhando para si mesmas": estas conhecem tudo dentro de si mesmas, tudo existe nelas como formas inteligíveis e como exemplos. Porém, a Causa Primeira não é conhecida por nenhum outro ser, porque a plenitude de sua essência não é comunicada, fica "para si mesma", ela somente é Causa, não é efeito de nada.

A descrição da Causa Primeira é, então, impossivel, porque uma descrição usa palavras, que são escolhidas por causa de'seu conteúdo, porque são sinais de uma determinada realidade, expressam um sentido. Ora, a Causa Primeira está acima de todas as coisas, porque ela é a sua çausa. Por isso ela não cai sob os sentidos. Apresenta-se aqui, claramente, o processo de conhecimento humano, o conhecimento através dos sentidos; deste conhecimento são indicados os níveis (veja a Sétima carta de Platão, a famosa "digressão filosófica"):" "[...] a descrição, realizada através de palavras, as palavras através da inteligência, a inteligência através do raciocínio, o raciocínio através da imaginação, a imaginação através dos sentidos". "A Causa Primeira está acima de tudo isto, porque ela não cai sob a razão, porque está acima de todas as coisas. Ela é a causa de tudo isto, sem ela mesma ser causada. Por isso nela não há espaço para "corrupção" ou "geração", realidades ligadas ao binômio causa e efeito, condição para o conhecimento através do raciocínio.

Para um estudo abrangente a respeito deste assunto no neoplatonismo, veja: Carabine, D., The unknown God, Peeters, 1995.

${ }^{10}$ Veja Jan G. J. Ter Reegen, A sétima carta de Platão, tradução e comentários; ad usum internum UECE, 1995.

LdC 5 (6), 61: "Isto ocorre porque a descrição só se faz através de palavras, as palavras através da inteligência, a inteligência através do raciocinio, o raciocínio através da imaginação, a imaginação através dos sentidos. Ora, a Causa Primeira está acima de todas as coisas, porque ela é a sua causa. É por isso que ela não cai sob os sentidos, a imaginação, a razão, a inteligência e a palavra; ela não é, portanto descritivel." 
Na Proposição 21(22) volta-se ao tema da inefabilidade: a Causa Primeira é o Ser Maior, Causa de tudo que está acima de tudo, por isso nenhum nome pode nomeá-la: ("A causa primeira está acima de todo nome com que é nomeado"). O homem, então, é limitado no seu conhecimento pela fato de receber as suas perfeições de outras causas, ele não é a própria perfeição, é um ser menor e como tal impossibilitado de aceder ao Ser Maior: por natureza o homem é um ser limitado, e seu conhecimento segue os limites do seu ser.

Uma reflexão a partir da essência da inteligência e da alma, pode fornecer mais detalhes a respeito de o Livro das Causas considerar o homem. Na Proposição 2 se lê o seguinte: "Todo ser superior ou é acima da eternidade e antes dela, ou com ela, ou depois dela e acima do tempo". Sem dúvida alguma, trata-se aqui das causas primánias: a Causa Primeira, a inteligência e a alma. O homem não pertence a essa trilogia. Mas, podemos, então, concluir que o homem é simplesmente no tempo, e conseqüentemente corruptível? Toda a doutrina platônica, e os neoplatônicos não abandonam-na, muito pelo contrário, afirmam categoricamente a imortalidade da alma, tanto através de argumentos "dialéticos" como por meio de mitos. ${ }^{12}$ Olhando mais de perto, e analisando a inteligência e a alma não somente como causas primeiras, nem como substâncias subsistentes, ${ }^{13}$ mas sim como substâncias segundas e compostas, encontram-se indicações sobre a verdadeira dimensão do homem, sua alma e sua inteligência.

Através da inteligência, que é una e única, estende-se a imortalidade na alma como uma perfeição infusa; a alma, por sua vez, estende-a àquela natureza que é capaz de recebê-la, no nosso caso à alma do homem. Pode-se, então, afirmar que o homem está na perspectiva da imortalidade e da eternidade, por causa de sua participação na inteligência e a na alma - mesmo sendo esta parcial e destrutível, porque o homem não é uma substância subsistente por si mesma. O homem não é inteligência pura, por isso não está com a eternidade: ele não conhece as coisas olhando ou voltando sobre a sua própria essência, mas sim através de imagens, da maneira que é própria à realidade sensível. A inteligência do homem, para conhecer, tem que se tornar "coextensiva à coisa extensa, de forma que uma de suas extremidades seja separada da outra" (Proposição 6(7),68-69); isto quer dizer movimento e corrupção, atributos impensáveis à inteligência primeira, mas próprios das coisas corporais.

O homem, ser inteligivel e sensivel, vive, então, como numa linha de demarcação: através de sua inteligência tem acesso tanto ao inteligível como ao sensível, porque a sua alma é efeito da inteligência e a causa do sensível. Sendo, porém, não primeira, a sua inteligência é menos universal e não conhece tudo, nem conhece em si mesma, mas reconhece as coisas nas formas que existem na sua

12 Veja, além dos estudos de autores clássicos como Guthrie e Crombie, entre tantos outros, os livros recentes em língua portuguesa de Margarida Nichel Paulo, Indagação sobre a imortalidade da alma em Platão (Edipucrs, 1996) e Bento Silva Santos OSB, A imortalidade da alma no Fédon de Platão (Edipucrs, 1999). Para um aprofundamento do uso do mito em Platāo, Jan G. J. Ter Reegen, "Uma introdução para a leitura dos mitos em Platão", Educação em Debate, 20/36/1998, 146-153, esp. 150 segs.

13 Veja para este assunto - substâncias subsistentes, LdC 25(26), 26(27), 27(28), 28(29). 
inteligência própria pela força da alma e da inteligência primeira, em última análise, pela ação da Causa Primeira. Porém, não se pode tirar da inteligência a "universalidade", mas ela existe de intensidade maior ou menor na medida em que se aproxima ou afasta do mundo sensivel. O homem está, por isso, entre o inteligivel e o sensivel, entre o que se move e o que não se move, entre o tempo e a eternidade, entre a corrupção e a subsistência por si. O seu conhecimento é, conseqüentemente, de uma universalidade menor, mas não está descartada.

\section{Conclusão}

Indicamos nesta comunicação algumas pistas. Existem outras, mas o caráter deste estudo impede um prolongamento da nossa investigação. Porém, não podemos deixar de fazer uma última observação: não encontramos no Livro das causas pistas para uma ética concreta, como por exemplo Plotino nos oferece amiúde. Será conseqüência da dependência excessiva da fonte, Elementos Teológicos de Proclo? Difícil de dizer, só podemos lamentar que um livro tão usado e espalhado e de tão grande influência, não tenha uns capítulos a mais, oferecendonos dados a respeito de uma vivência.

Mas, se considerarmos bem, basta o grande princípio que norteia tudo no $L i$ vro das causas: Deus é o absolutamente Primeiro, Ele é o criador de que tudo depende.

Termino com as palavras do Livro das causas: "Completus est sermo... Laus regum regi, quia tandem coepta peregi. Deo Gratias." 